\title{
The Measurement of Ice Nucleus Concentrations by Means of Millipore Filters
}

\author{
E. K. Bigg, S. C. Mossop, R. T. Meade and N. S. C. Thorndike \\ Commonweallh Scientific and Industrial Research Organization, Radiophysics Laboratory, Sydney, Australia
}

(Manuscript received 10 October 1962)

\begin{abstract}
Details are given of a technique for measuring ice nucleus concentrations using the cellulose ester membrane filters known as "millipores." Some of the errors which may occur are examined in detail and it is shown that a properly designed procedure can give measurements comparable with those obtained by cold chambers.
\end{abstract}

\section{Introduction}

A method of measuring ice nucleus concentrations by means of the cellulose ester filters marketed under the trade name "millipore"1 was described briefly by Bigg, Miles and Heffernan (1961). The technique has the advantage of being a comparatively simple and effective one. At the same time it is liable to be seriously influenced by several factors unless due allowance is made in the experimental procedure. It is proposed to examine some of these factors in the present paper.

\section{Description of the method}

An outline of the method used in measuring ice nucleus concentration will now be given.

(i) A known volume of air is drawn through a filter backed with a supporting disk, known as a "nutrient pad" by the filter manufacturers. The number of ice crystals obtained does not increase linearly with the volume sampled, an effect which is discussed in Section 5.

(ii) After exposure, the filter is placed in a thickwalled metal dish $5 \mathrm{~cm}$ in diameter and $1 \mathrm{~cm}$ deep which has previously been covered thinly and evenly with a non-volatile grease to ensure that the filter adheres firmly to the metal, so making good thermal contact with it. It also prevents nucleation on the metal surface.

(iii) The container and filter are stored in a wellglycerined cold chamber for long enough to ensure that the filter achieves thermal equilibrium.

(iv) A damp nutrient pad at $20 \mathrm{C}$ is placed over the container for a fixed period, after which it is removed. The number of crystals obtained depends critically on this procedure which is discussed in more detail in Section 9.

(v) A supercooled ice-detecting solution is poured evenly over the filter and the ice crystals counted when they have grown sufficiently. For temperatures of $-15 \mathrm{C}$ or colder a sucrose solution is very suitable. Its strength

\footnotetext{
1 By the Millipore Corporation, Bedford, Mass.
}

should be adjusted so that ice crystals in it are in equilibrium at about $2 \mathrm{C}$ warmer than the temperature at which the crystals are to be detected. To avoid spontaneous nucleation, filtration of the solution through a millipore before use is desirable. The solution must not be poured until it is colder than the equilibrium temperature.

At temperatures above $-15 \mathrm{C}$ the ice crystals which grow in sucrose solutions are transparent and difficult to count. Sodium silicate solution is an excellent substitute with the advantages that it gives opaque crystals, supercools readily and does not destroy ice embryos at temperatures almost as warm as $0 \mathrm{C}$. A specific gravity of 1.42 is suitable for temperatures of $-10 \mathrm{C}$ to $-15 \mathrm{C}$. Sucrose and silicate solutions give the same average counts on filters exposed in parallel. A typical photograph of ice crystals developed upon an exposed filter is shown in Fig. 1.

\section{Humidification of filters}

In studying ice nuclei, the main aim is usually to assess their behavior in the atmosphere, where they are never subjected to a humidity significantly (in the ice nucleation context) higher than water saturation. Ideally therefore the measurement should be made at water saturation. If a supersaturation is used, the rate of nucleation is increased, according to theory, and there is a rise in temperature accompanying condensa-

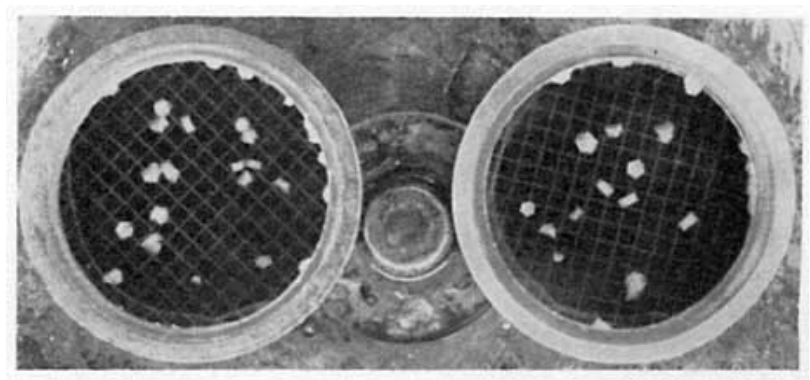

Fig. 1. Ice crystals grown upon nuclei captured on millipore filters. 
tion which counters this effect, so that the exact meaning of the measurement is obscure.

One way to ensure water saturation is to produce droplets at the top of a very stable temperature gradient and allow them to fall, while evaporating, on the filter. This is the reason for using a relatively deep container $(1 \mathrm{~cm})$; with a temperature gradient of $+30 \mathrm{C}$ per $\mathrm{cm}$ the droplets, not the filter, take up the diffusing water vapor as they fall. It takes a certain time for the droplets to grow and fall to the filter, and the ice crystal concentration measured beyond this time should increase with the duration of humidification in the way discussed by Fletcher (1958). It is not advisable to continue humidification beyond about two minutes, since there is a risk of using up the available condensation nuclei and obtaining frost splinters from the walls of the container after long exposures. Such a short duration of humidification may cause some scatter in experimental results because the ratio of one minute to $\eta$ minute counts depends on the temperature spectrum of the nuclei, but this is preferable to the possible experimental errors which may arise with longer durations.

Fig. 2 shows the way in which the number of ice crystals counted on filters having approximately equal numbers of nuclei, increases with the duration of humidification. It will be seen that strict control of the humidification process is essential.

\section{Background counts}

Most white filters yield 0 to 3 crystals when developed at $-15 \mathrm{C}$ without sampling any air. Since one aims at total counts greater than 10 to obtain statistical reliability, the background count is not normally a nuisance.

The picture is different when some black filters are used. Although developed ice crystals are much more conspicuous on the blacks, which were therefore originally used for the method, it has been found that occasional batches have background counts of 20 to 100 at $-15 \mathrm{C}$. Since, according to the manufacturers, the filters are identical with the whites except for the nigrosin dye used, the variability must be attributed to the dye. If blacks are used, they should first be tested for background counts.

\section{Non-linearity of ice crystal counts with sampled volume}

At first sight the greatest advantage of the filtration method of counting ice nuclei is its ability to sample large volumes of air without the necessity of using unwieldy containers. Unfortunately there is a severe limitation to the use of filters in high volume sampling.

It was soon obvious from simultaneously exposing filters to various volumes of air that the mean apparent concentration decreases significantly with the volume of air filtered. Similar results were obtained in rural and industrial areas, and a comparable pair of experiments is shown in Fig. 3.

A sequence of daily comparisons was made between a filter which had sampled $100 \ell$ and one which had concurrently sampled $1000 \ell$ of air. If the crystal count on the $100 \ell$ filter was adjusted to the mean value (57) for $100 \ell$ on the curve in Fig. 3, then the same adjustment to the $1000 \ell$ count yielded the apparent concentrations

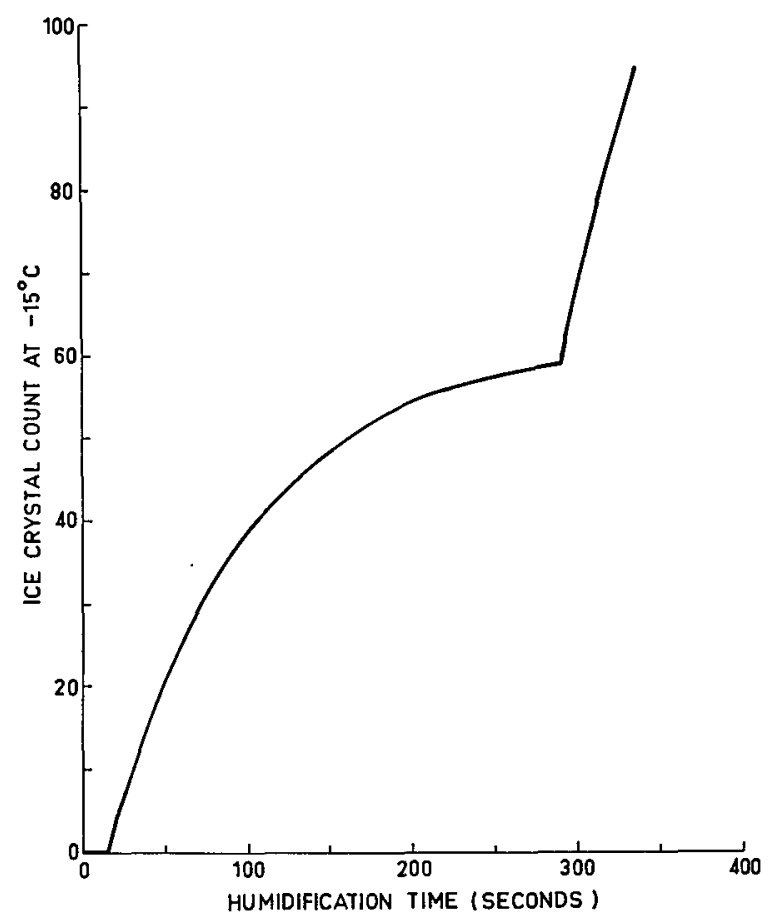

FIG. 2. Effect of duration of humidification upon number of ice crystals developed upon similarly exposed millipores.

THE DECREASE OF APPARENT ICE NUCLEUS CONCENTRATION WITH INCREASING VOLUME OF AIR FILTRATION

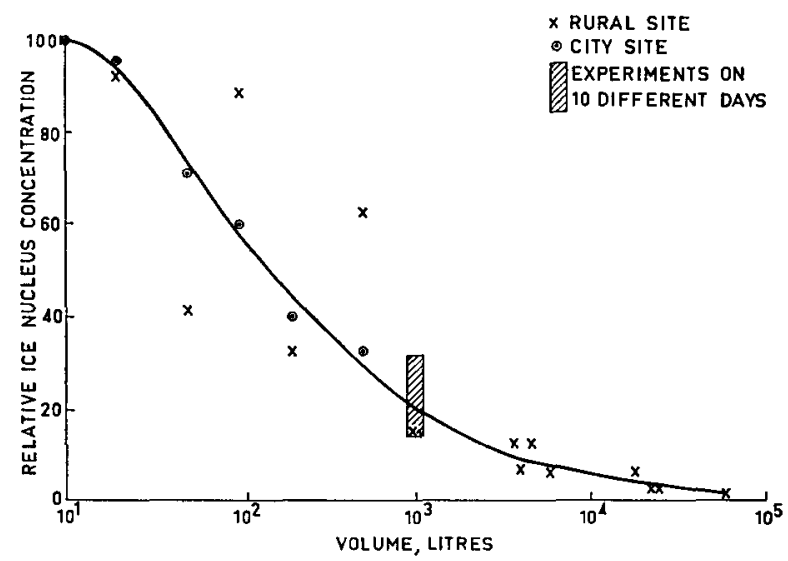

FIG. 3. Effect of volume of air sucked through millipore filters upon the apparent concentration of ice nuclei. Results are normalized to a concentration of 100 for an air volume of 10 liters. 
shown by the hatched area in the figure. It is doubtful whether this variation is significant as the $100 \ell$ count was of ten only about 10 crystals.

Another way of investigating this effect is to put a large number of silver iodide nuclei on filters, then find the decrease in the number effective as increasing amounts of room air are drawn through the filters. The means from three experiments on separate days, each experiment using 12 filters at temperatures of $-8,-10$, and $-12 \mathrm{C}$ are shown in Fig. 4 . The rates of loss are similar to the apparent concentration decrease of Fig. 3, thus ruling out the possibility that the nonlinearity is caused by changing collection efficiencies.

Four other reasons have been considered:

1) Inert particles may cover nucleation sites;

2) The majority of ice nuclei may be lodged slightly below the filter surface, and the presence of a hygroscopic particle above it or closer to the surface could prevent water saturation being reached at the nucleus during humidification;

3) "Poisoning" of nuclei by vapors in the air may occur;

4) Particles may be driven deeper into the filter by the passage of air after they have been captured.

The first suggestion requires an impossibly large total cross-sectional area for the natural aerosols. To cause a noticeable decrease in active nuclei $1000 \mathrm{~cm}^{-3}$ particles of $1-\mu$ diameter or $10^{5} \mathrm{~cm}^{-3}$ of $0.1-\mu$ diameter particles would be required, and such concentration is not found in rural areas.

The second cause requires approximately $1000 \mathrm{~cm}^{-3}$ hygroscopic particles, irrespective of size, and this is a reasonable figure in continental air. The explanation requires further investigation.

Drawing filtered air through millipores having a known concentration of nuclei on their surfaces showed that the remaining explanations are inadequate to explain the apparent concentration decrease, for much less change occurred than when unfiltered air was sampled, as shown in Fig. 4.

In the absence of a better explanation the interference of hygroscopic particles with the nucleation process seems to be the most satisfactory, but cannot be regarded as established.

\section{The particle size caught by filters}

An idea of the retention of filters was obtained by mounting a $0.1-\mu$ nominal pore size filter behind a $1.2-\mu$ filter, the two being spaced several $\mathrm{cm}$ apart in a special holder. In an atmosphere containing silver iodide, the $0.1-\mu$ filter did not catch a significant number of nuclei active at $-15 \mathrm{C}$. This implies that a $1.2-\mu$ filter retains all particles $0.1 \mu$ in diameter, and since the $0.1-\mu$ filter itself would retain particles smaller than the pore diameter, a $1.2-\mu$ filter evidently catches particles down

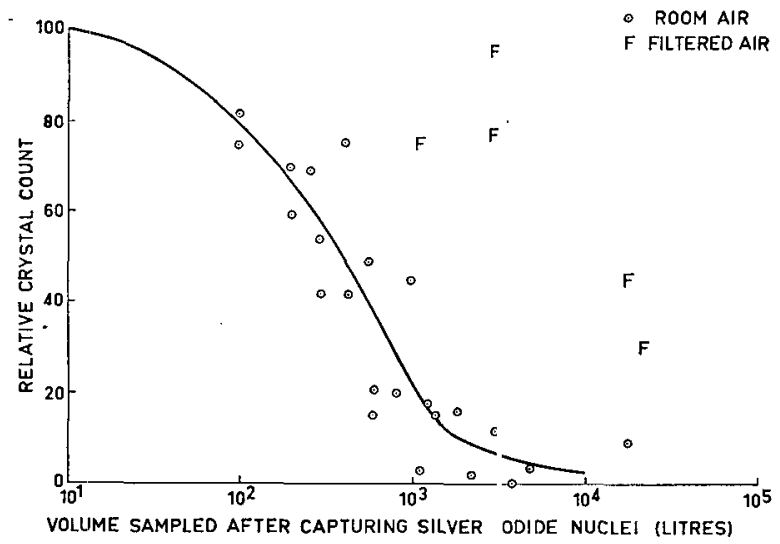

FIG. 4. The decrease in the number of effective silver iodide nuclei on filters used for further air filtration.

to the smallest silver iodide parti le active at $-15 \mathrm{C}$. According to Fletcher (1959) thi; is of the order of $0.05-\mu$ diameter (for sublimation at water saturation).

An experiment was performed comparing the mean concentrations of silver iodide nuclei measured with filters of different pore sizes, using a two-minute count in mixing cold chamber as refere nce. The results are shown in Table 1, the volumes sampled being less than $10 \ell$.

TABLE 1. Mean concentrations of silver iodide nuclei compared for filters of different port: size.

\begin{tabular}{cccc}
\hline $\begin{array}{c}\text { Temperature } \\
(\text { deg C) }\end{array}$ & $\begin{array}{c}\text { Pore size } \\
(\mu)\end{array}$ & $\begin{array}{c}\text { Numiber of } \\
\text { filters }\end{array}$ & $\begin{array}{c}\text { Mean \% of } \\
\text { cold chamber } \\
\text { concentration }\end{array}$ \\
\hline-12 & 1.2 & 15 & 76 \\
-17 & 0.1 & 10 & 77 \\
-17 & 1.2 & 10 & 81 \\
-17 & 5.0 & 4 & 46 \\
\hline
\end{tabular}

This table shows that the $5.0 \mu$ filters only catch about half the available ice nucei active at $-17 \mathrm{C}$, which have a minimum diameter of the order of $0.04 \mu$ or 1 per cent of the pore size.

\section{Comparison with cold chambers}

The important point for our work is whether the filters count as many natural ice nuclei as a cold chamber. A fair test requires a fixed sampling volume

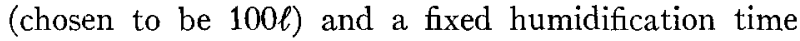
(one minute). The reference cold chamber was maintained at water saturation for two minutes. Note that from Fig. 3, one should multiply the millipore concentration by about 1.75. Cold box volume was 6 liters. It is clear from Table 2 and the preceding table that the filtration method is entirely zomparable with the cold chamber, as long as the two major effects of humidification and sampled vol tme are taken into 
account. It should be noted that the expansion cold chamber does not agree as closely as this with the mixing chamber. The latter produces conditions more closely comparable with those found in natural atmospheric nucleation processes.

TABLE 2. Mean concentrations of silver iodide nuclei compound with cold chambers.

\begin{tabular}{|c|c|c|c|c|c|c|c|}
\hline \multirow{2}{*}{$\begin{array}{c}\begin{array}{c}\text { Tempera- } \\
\text { ture } \\
\text { (deg C) }\end{array} \\
-15 \\
-17.5 \\
-22\end{array}$} & \multirow{2}{*}{$\begin{array}{c}\begin{array}{c}\text { Number } \\
\text { of } \\
\text { filters }\end{array} \\
24 \\
24 \\
24\end{array}$} & \multicolumn{2}{|c|}{$\begin{array}{cc}\text { Mean concentration } \\
\text { Black } & \text { White } \\
0.8 \mu & 1.2 \mu \\
\end{array}$} & \multicolumn{2}{|c|}{$\begin{array}{l}\% \text { of } \\
\text { reference } \\
\text { cold box } \\
\text { concen- } \\
\text { tration } \\
\text { Black White }\end{array}$} & \multicolumn{2}{|c|}{$\begin{array}{l}\% \text { Allowing } \\
\text { for sampling } \\
\text { error }\end{array}$} \\
\hline & & $\begin{array}{r}65 \mathrm{~m}^{-3} \\
317 \mathrm{~m}^{-3} \\
101 \mathrm{~m}^{-3}\end{array}$ & $\begin{array}{r}67 \mathrm{~m}^{-3} \\
307 \mathrm{~m}^{-3} \\
83 \mathrm{~m}^{-3}\end{array}$ & $\begin{array}{l}35 \\
54 \\
57\end{array}$ & $\begin{array}{l}36 \\
53 \\
47\end{array}$ & $\begin{array}{r}61 \\
95 \\
100\end{array}$ & $\begin{array}{l}63 \\
92 \\
82\end{array}$ \\
\hline
\end{tabular}

Lodge and Bravo (1962) have described a "heat treatment" method for improving the performance of black millipores. Lodge has kindly furnished us with six treated and six untreated type HA $(0.8 \mu)$ millipores, which we compared with type RA $(1.2 \mu)$ white millipores by simultaneous filtration. Results were:

$\begin{array}{lllr} & & \text { Total } \\ \text { Treated HA } & 13,26,28,25,20,22 & 134 \\ \text { Untreated HA } & 15,8,8,9,8,9 & 57 \\ \text { White RA } & 11,12,19,9,11,9 & 71\end{array}$

It is clear that the treatment does increase the apparent concentration of ice nuclei. It is not obvious that this constitutes a sufficient advantage in normal use to justify the process.

\section{Reproducibility of results}

Filters were exposed simultaneously in groups of four, and the percentage of each count relative to the mean of the group was noted. Fig. 5 shows the distribution of results for 100 filters, and shows that nearly half the measurements lay within \pm 10 per cent of the mean, and only 4 per cent were further than 50 per cent from

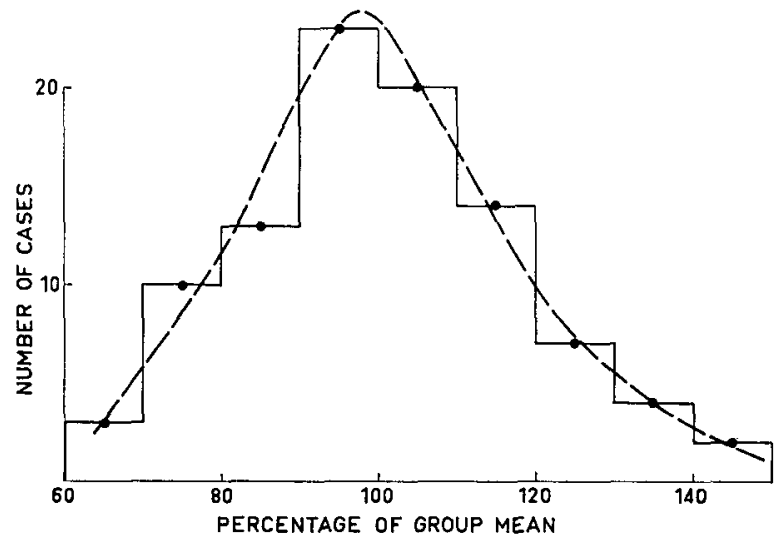

FIG. 5. The reproducibility of ice nucleus counts using the millipore technique. the mean. This degree of order is quite as good as one would normally obtain using four cold chambers.

\section{Storage of filters}

The "keeping qualities" of ice nuclei will no doubt depend on the nature of the nuclei, but all experiments with natural nuclei so far have indicated no diminution in numbers on covered filters which have been stored for one month. This represents another major advantage of the filtration method--sampling and processing need not be simultaneous. This is of particular value in high-altitude nucleus measurements.

\section{The influence of ambient humidity}

The great effectiveness of the filters in retaining very small particles is no doubt due partly to the high electrostatic charge which builds up quite rapidly during filtration. The pressure drop across a type RA filter at a flow rate of $20 \ell$ per min exceeds $3 \mathrm{~cm}$ of mercury and this may lead to condensation, wetting of the filter and reduction of charge in high ambient humidities. This difficulty has not been obvious during our tests, possibly because sufficiently high humidities have been uncommon, but should be borne in mind in an experimental program. Lower sampling rates would avoid the difficulty altogether.

\section{Conclusions}

In view of these considerations it may be concluded that the measurement of ice nucleus concentrations by filtration is entirely feasible. It has the great virtues of simplicity and reliability of equipment; it produces results entirely comparable with those from cold chambers and as reliable. There is also the advantage that the air sampling and ice nucleus counting need not be simultaneous, so that widespread sampling by untrained observers is possible, simply by forwarding the filters to a central processing laboratory.

If ice nucleus measurements have a future in forecasting meteorology it is clear that this is the method to use.

However, close attention must be paid to the factors which vary the apparent concentration, notably the duration and method of humidification and the volume of air filtered.

\section{REFERENCES}

Bigg, E. K., G. T. Miles and K. J. Heffernan, 1961: Stratospheric ice nuclei. $J$. Meleor, 18, 804-806.

Fletcher, N. H., 1958: Time lag in ice crystal nucleation in the atmosphere. Part 2, Theoretical. Bull. Obs. Puy de Dome, 1, 11-18.

- 1959: On ice crystal production by aerosol particles. $J$. Meteor., 16, 173-180.

Lodge, James P., and H. Bravo, 1962: An improved technique for the determination of freezing nuclei concentrations, $B u l l$. Obs. Puy de Dome, 10, 81-86. 